\title{
Diffusion Bonding and Brazing of Advanced Materials
}

\author{
Sónia Simões ${ }^{1,2}$ (1) \\ 1 CEMMPRE, Department of Metallurgical and Materials Engineering, University of Porto, 4200-465 Porto, \\ Portugal; ssimoes@fe.up.pt \\ 2 INEGI-Institute of Science and Innovation in Mechanical and Industrial Engineering, 4200-465 Porto, \\ Portugal
}

Received: 8 November 2018; Accepted: 14 November 2018; Published: 16 November 2018

check for updates

\section{Introduction and Scope}

Advanced materials generally require the development of novel joining techniques, as this is crucial to integrate them into functional structures and to widen their application field. Additionally, joining constitutes a technology, which influences all the industrial sectors, playing a key role in the economic and social development of a country.

Diffusion bonding and brazing are two straightforward techniques for producing sound and reliable joints since these processes are capable of joining a wide range of materials of interest in the aerospace industry, as well as in many other industrial applications, offering remarkable advantages over conventional fusion welding processes.

Production of dissimilar joints is also crucial for application of these materials. For instance, the combination of advanced ceramic with lightweight alloys, such as titanium or aluminum alloys, is quite attractive, combining the extraordinary properties of the two materials and extending the potential applications particularly into components for the automotive and aerospace industries. The major challenge in the production of these joints is to overcome the enormous differences in mechanical behavior, as well as thermal expansion coefficients and so new approaches need to be developed to produce dissimilar joints successfully.

\section{Contributions}

The current special issue is composed of papers that present the recent progress in the joining technologies of advanced materials, with a particular attention for the microstructure-mechanical property relationships of the joints.

The successful production of dissimilar joints, such as advanced ceramics with lightweight alloys, titanium, or aluminum alloys, is quite attractive, combining the extraordinary properties of the two materials and extending their potential applications, particularly into components for the automotive and aerospace industries. The review paper of this special issue [1] provides an excellent description of the recent progress in the production of these dissimilar joints by diffusion bonding and brazing processes. However, on the basis of this review, it is clear that more research work is needed in order to promote process improvements in order to make them feasible in these industrial sectors.

The other outstanding papers that are part of this special issue were selected because they are examples of crucial work that bring industry closer to achieving this goal. Although some alternative methods presented produce sound joints using advanced materials, they all share similar purpose: developing new approaches in order to produce joints with expected mechanical properties under less demanding processing conditions compared to conventional processes.

The successful joining of titanium alloys is crucial for the fabrication of highly loaded aerospace components. Brazing and diffusion bonding is the most suitable process for this purpose. These joining 
processes present numerous challenges, such as the formation of brittle intermetallic interphases, the achievement of good mechanical properties without compromising the base materials, and the use of less demanding processing condition. Gussone et al. [2] present a study of the interphase formation in brazed joints, consisting of different titanium alloys (Ti-CP2, Ti-CP4, Ti-6Al-4V, Ti-6Al-2Mo-4Zr-2Sn) using $\mathrm{Ag} 28 \mathrm{Cu}$. The results of this study demonstrate that besides the already explored approaches for the dissimilar titanium alloys joints; i.e., modification of the brazing solders (e.g., by Sn or In) and application of interlayers (e.g., with Ag or Pd) — the composition of the base material can play a remarkable role. The diffusion bonding is the other process reported for the dissimilar joints. However, the processing conditions normally involved in these processes make them less attractive economically. Considerable effort has been made in the development of new brazing alloys or interlayers that make brazing and diffusion bonding processes more suitable for industrial implementation. Reactive multilayer thin films are an alternative interlayer for reducing the temperature and/or the pressure needed for diffusion bonding. Simões et al. [3] investigated the effectiveness of using the $\mathrm{Ni} / \mathrm{Al}$ reactive nanolayers for the dissimilar joints between titanium alloys. The dissimilar joining of titanium alloys assisted by nanolayers is achieved by the reaction of the multilayers, which provides good quality, defection-free interfaces at less demanding processing conditions.

In order to widen the applications of these alloys, the dissimilar joints of titanium alloys with other materials like Ni-based superalloys are also very interesting. The joining of a lightweight like TiAl alloy to other high-temperature materials can allow the production of extraordinarily complex components. Brazing and diffusion bonding are attractive options to produce dissimilar joints. The principal challenge in this field is to promote the formation of the joints under less demanding processing conditions, composed by an interface with similar mechanical properties of the base materials. Simões et al. [4] demonstrated that the brazing filler has a crucial influence on overcoming these challenges. The development of new brazing fillers can contribute to decreasing the bonding conditions as well as the formation of an interface composed of the microstructure that will not compromise the mechanical properties of the joints.

Other lightweight materials are also extremely interesting for various industrial sectors. An example of this is magnesium and magnesium alloys (especially AZ31) since they are increasingly being used as a substitute for many traditional alloys. Transient liquid phase (TLP) bonding is one of the most reported bonding processes for the production of $\mathrm{Mg}$ based joints. However, the used interlayers have to be well selected in order to promote a quality bonding of these lightweight alloys. AlHazza et al. [5] investigated the use of $\mathrm{Cu}$ coatings and $\mathrm{Cu}$ coatings with Sn interlayer in the TLP bonding of an AZ31 alloy. The presence of the Sn interlayer promotes an improvement in the joint strength, revealing an excellent approach to apply in the implementation of this joining process.

The 7075 aluminum alloy is also used in aircraft, automotive, and electronic industries. The joining technologies play a role in the production of the components for these industries. However, the welding processes revealed to be very challenging for aluminum and aluminum alloys. Although TLP bonding is an interesting joining process for these alloys, there are some limitations that make the implementation of this process difficult. Meengam el al. [6] investigated the possibility of using a ZA27 zinc alloy interlayer to bond 7075 aluminum alloy by TLP. The authors revealed that it was possible to obtain a sound dissimilar joint but the bonding time and temperature have a crucial influence on the microstructure interface that is an intimate bond with the mechanical properties of the joints.

The joining of aluminum alloys to other materials such as steel can be also extremely interesting. The joining of these dissimilar joints through a fusion welding process present some problems, such as hot cracking. Muhamed et al. [7] have shown that the brazing of 7075 aluminum alloy to steel can be conducted using an Al-Si-Zn base filler metal.

Aluminum foam sandwich (AFS) panels are multifunctional, stiffer, and offer excellent corrosion resistance for many industrial applications, including automotive, marine, aerospace, construction, and railway. AFS are made of thin rigid Al-alloy sheets (facing sheets) joined with a porous, lightweight Al-alloy foam (core). Bangash et al. [8] investigated the production of AFS by brazing 
using metal glasses. Sound joints were achieved using two different Al-based metal glasses. However, the formation of hard and brittle intermetallic phases was observed, which compromise the mechanical properties of the joints. Although the production of AFS needs improvement and optimization, this work shows a good approach to produced AFS that can be usefully applied at an operational temperature up to $520^{\circ} \mathrm{C}$.

Advanced ceramics have attractive properties, such as high wear resistance, high thermal stability as well as high thermal and electrical conductivities. It is known that some of the advanced ceramics like alumina, silicon nitride, and zirconia, are also well established in the electronics, aerospace, nuclear, and automotive industries. However, their inherent brittleness, high cost, and high hardness limit the production of large and complex shape components. The successful application of these advanced ceramics depends strongly on the joining processes. Li et al. [9] present an approach for the joining between porous $\mathrm{Si}_{3} \mathrm{~N}_{4}$ to dense $\mathrm{Si}_{3} \mathrm{~N}_{4}$ using metal glasses. The brazing of this ceramic can be conducted with success at 1550,1600 , and $1650{ }^{\circ} \mathrm{C}$. The bonding temperature has a strong influence on the infiltration of the glass filler on the base material that can impact on the formation of a strong or weak bonding between the base materials.

Conflicts of Interest: The author declares no conflict of interest.

\section{References}

1. Simões, S. Recent Progress in the Joining of Titanium alloys to Ceramics. Metals 2018, 8, 876. [CrossRef]

2. Gussone, J.; Kasperovich, G.; Haubrich, J.; Requena, G. Interfacial Reactions and Fracture Behavior of Ti Alloy-Ag28Cu Brazing Joints: Influence of Titanium Alloy Composition. Metals 2018, 8, 830. [CrossRef]

3. Simões, S.; Viana, F.; Ramos, A.S.; Vieira, M.T.; Vieira, M.F. Microstructural Characterization of Dissimilar Titanium Alloys Joints Using Ni/Al Nanolayers. Metals 2018, 8, 715. [CrossRef]

4. Simões, S.; Tavares, C.J.; Guedes, A. Joining of $\gamma$-TiAl Alloy to Ni-Based Superalloy Using Ag-Cu Sputtered Coated Ti Brazing Filler Foil. Metals 2018, 8, 723. [CrossRef]

5. AlHazaa, A.N.; Shar, M.A.; Atieh, A.M.; Nishikawa, H. Transient Liquid Phase Bonding of Magnesium Alloy AZ31 Using $\mathrm{Cu}$ Coatings and $\mathrm{Cu}$ Coatings with Sn Interlayers. Metals 2018, 8, 60. [CrossRef]

6. Meengam, C.; Dunyakul, Y.; Maunkhaw, D.; Chainarong, S. Transient Liquid Phase Bonding of Semi-Solid Metal 7075 Aluminum Alloy using ZA27 Zinc Alloy Interlayer. Metals 2018, 8, 637. [CrossRef]

7. Muhamed, M.N.; Omar, M.Z.; Abdullah, S.; Sajuri, Z.; Zamri, W.F.H.W.; Abdullah, M. Brazed Joint Interface Bonding Strength of AR500 Steel and AA7075 Aluminium Alloy. Metals 2018, 8, 668. [CrossRef]

8. Bangash, M.K.; Ubertalli, G.; Saverio, D.D.; Ferraris, M.; Jitai, N. Joining of Aluminium Alloy Sheets to Aluminium Alloy Foam Using Metal Glasses. Metals 2018, 8, 614. [CrossRef]

9. Li, L.; Sun, L.; Liu, C.; Wang, X.; Wang, X.; Zhang, J. Microstructure and Properties of Porous $\mathrm{Si}_{3} \mathrm{~N}_{4} / \mathrm{Dense}$ $\mathrm{Si}_{3} \mathrm{~N}_{4}$ Joints Bonded Using RE-Si-Al-O-N (RE $=\mathrm{Y}$ or $\left.\mathrm{Yb}\right)$ Glasses. Metals 2018, 7, 500. [CrossRef]

(C) 2018 by the author. Licensee MDPI, Basel, Switzerland. This article is an open access article distributed under the terms and conditions of the Creative Commons Attribution (CC BY) license (http:/ / creativecommons.org/licenses/by/4.0/). 